\title{
Management of Diabetic Retinopathy
}

\author{
Nova Herdana ${ }^{1}$, AK Ansyori ${ }^{1}$, Ramzi Amin ${ }^{1}$ \\ ${ }^{1}$ Department of Ophthalmology, Faculty of Medicine, University of Sriwijaya, Indonesia \\ *Corresponding author email: nova.herdana@gmail.com
}

\begin{abstract}
Introduction. Diabetic retinopathy (RD) is one of the most common complications of diabetes mellitus, and is a major cause of blindness in patients aged 20-64 years worldwide. The main principle of the management of $\mathrm{RD}$ is to prevent, inhibit and overcome complications that occur. Vitrectomy, laser photocoagulation, intravitreal anti VEGF injection become modalities in RD therapy. If PDR has occurred, vitreous hemorrhage can occur or the retina is attracted by proliferation tissue, vitrectomy should be performed.

Case Presentation. The patient is a 52-year-old man who came with the main complaint that both eyes have blurred slowly since \pm 6 months ago. Blurred vision is not accompanied by red eyes, there is smoke-like vision. In the past the history of the disease obtained a history of DM 15 years of irregular control and hypertension of 3 years with regular control, a history of spectacles present. The ophthalmological examination of the right eye revealed a vision of 6/30 pH (-), TIOD within normal limits, and a grade II nuclear cataract in the lens. Right eye fundoscopy revealed decreased foveal reflexes and exudates in the macula, dot, blot, flameshaped bleeding in 4 quadrants of the retina, exudate, venous beading, micro-aneurism. Management in these patients is pars plana vitrectomy, endolaser, and intravenous OS antiVEGF injection under general anesthesia. Whereas the right eye was intravitreal photocoagulation laser and anti-VEGF laser (done 2 weeks before).

Conclusion. A case of advanced left eye PDR with severe NPDR and right eye DME and grade II nuclear cataracts has been described in both eyes. Patients treated with laser photocoagulation in the right eye. In the left eye pars plana vitrectomy, endolaser, and intravitreal bevacizumab injection. Sharp vision of the left eye progressed postoperatively.
\end{abstract}

Keyword. management, retinopathy, diabetic retinopathy 


\section{Introduction}

Diabetic retinopathy (RD) is one of the most common complications of diabetes mellitus, and is a major cause of blindness in patients aged 20-64 years worldwide. The World Health Organization (WHO) states diabetic retinopathy (RD) is the cause of blindness in $4 \%$ of all 45 million blind people in the world, and this number will increase rapidly along with the increasing number of people with DM. The prevalence of RD in people with diabetes mellitus increases with age and duration of diabetes. After 5 years of DM diagnosis, $25 \%$ of people with type $1 \mathrm{DM}$ have diabetic retinopathy, while $84 \%$ of people with type 2 diabetes mellitus ${ }^{1-3}$

$\mathrm{RD}$ is a disease that does not have alarming symptoms at first, but the progression of RD can cause blindness. The main principle of the management of RD is to prevent, inhibit and overcome complications that occur. Vitrectomy, laser photocoagulation, intravitreal anti VEGF injection become modalities in RD therapy. If PDR has occurred, vitreous hemorrhage can occur or the retina is attracted by proliferation tissue, vitrectomy should be performed.

Cheng et al (2001) in the Vitrectomy for Macular Hole Study reported the progression of nuclear cataracts occurring in post-vitrectomy patients by $81 \%$ at 6 months follow-up. The formation of post-vitrectomy cataracts is thought to be related to structural disruption of the vitreous body which causes increased oxygen exposure to the lens and thus results in the formation of nuclear cataracts. In addition, intraoperative maneuvers can affect the lens and capsule, resulting in humorous aquous or the body of the vitreous corpus can enter the lens structure so that the lens quickly becomes cloudy. ${ }^{3-6}$

Reported a case of diabetic retinopathy in both eyes, which was managed by intravitreal anti-VEGF injection and laser photocoagulation in the right eye, then vitrectomy, endolaser, and intravitreal injection of anti-VEGF in the left eye followed by the formation of complicated OS cataracts. The management of this case is followed by cataract extraction and IOL implantation.

\section{Case Report}

A man, 52 years old, out of town address, self-employed, came to the eye clinic on July 16,2014 . Anamnesis of the main complaint was that both eyes blurred slowly since \pm 6 months before entering the hospital. 


\section{SSTO}

\section{JOURNALOFOPHTHALMOLOGY}

Travel history of the disease is since \pm 6 months before entering the hospital, sufferers feel the vision of both eyes blurred slowly without accompanied by red eyes. Views such as smoke-covered (+), views such as viewing in tunnels (-), pain (-), such as seeing as flying objects (-), complaints of dizziness and headaches are absent.

Since \pm 1 month before entering the hospital the vision of both eyes feels increasingly blurred, the left eye is more blurred than the right eye. Red eye (-), smoke-like (+) vision. Patients seek treatment at the local Regional General Hospital and are referred to RSMH.

Past medical history is a history of eyeball trauma, history of glasses (+) since 12 years ago, to read and see far, history of hypertension since \pm 3 years ago, regular treatment, history of DM (+) since \pm 15 years, no regular treatment, history of drug allergy (-), history of intravitreal injection of right eye Avastin 2 weeks ago.

Physical examination generalist status General state: Good, Consciousness: compos mentis, Blood Pressure: 160/90 mmHg, Pulse: $88 x$ / minute, Temperature: $36.8^{\circ} \mathrm{C}$, Respiration: $24 \mathrm{x} /$ minute.

Ophthalmology status table

\begin{tabular}{|c|c|c|}
\hline & OD & OS \\
\hline Vision & $6 / 30 \mathrm{pH}(-)$ & $1 / 60 \mathrm{pH}(-)$ \\
\hline Intraocular pressure & $15,6 \mathrm{mmHg}$ & $15,6 \mathrm{mmHg}$ \\
\hline Eyeball position & \multicolumn{2}{|l|}{ Ortoforia } \\
\hline Eyeball movement & Good in all directions & Good in all directions \\
\hline Palpebra & Quite & Quite \\
\hline Conjunctiva & Quite & Quite \\
\hline Cornea & Clear & Clear \\
\hline Front Eye Chamber & Medium, clear, VH4 & Medium, clear, VH4 \\
\hline Sliced & Good image & Good image \\
\hline Pupil & $\begin{array}{l}\text { Round, central, RC (+), } \varnothing \\
3 \mathrm{~mm}\end{array}$ & $\begin{array}{l}\text { Round, central, RC (+), } \varnothing \\
3 \mathrm{~mm}\end{array}$ \\
\hline Lens & Cloudy, N II & Cloudy, N II \\
\hline Vitreus & Clear & Bleeding (+) \\
\hline Posterior Segment & RFOD (+) & RFOS (+) \\
\hline
\end{tabular}




\begin{tabular}{|c|c|c|}
\hline Papil & $\begin{array}{l}\text { Round, firm boundary, } \\
\text { red N, c / d } 0.3 \text { a / v } 2 / 3, \\
\text { NVD (-) }\end{array}$ & Details are difficult to judge \\
\hline Macula & RF (+) $\downarrow$, exudate $(+)$ & Details are difficult to judge \\
\hline Retina & $\begin{array}{l}\text { Details difficult to assess } \\
\text { Bleeding (+) dot, blot, } \\
\text { flame-shaped, in } 4 \\
\text { quadrants, exudate (+), } \\
\text { venous beading (+) in } 2 \\
\text { quadrants, micro- } \\
\text { aneurism (+), NVE (-) }\end{array}$ & Details are difficult to judge \\
\hline
\end{tabular}

Pre-operative fundus photo

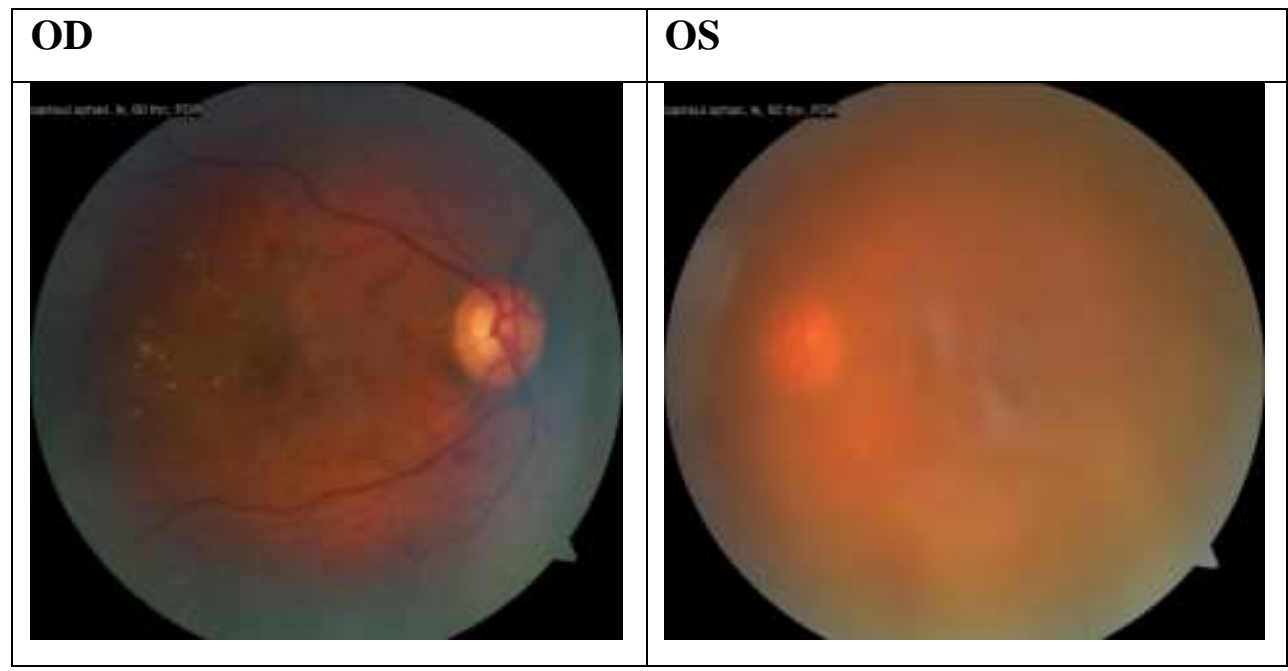




\section{SRIWIJAYA JOURNAL OF OPHTHALMOLOGY}

ज्ञ०O

Retinal drawing

$\underline{\text { OD }}$

$\underline{\text { os }}$
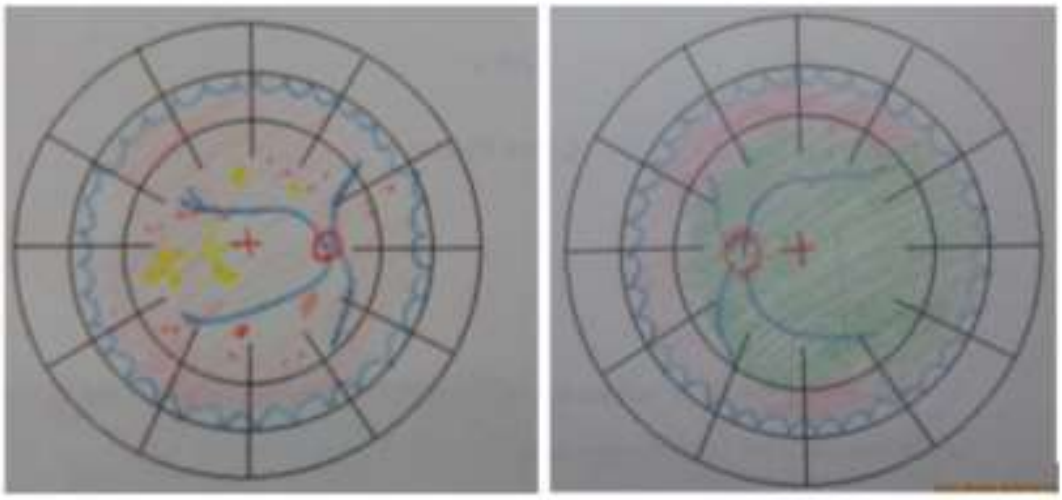

Image of USG OS

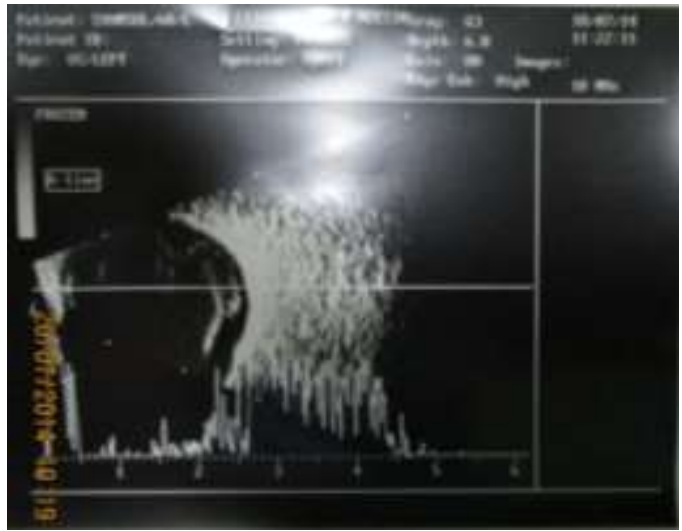

Vitreus: echogenic, moderate reflectivity, high mobility, Retina: intact, choroid: not thickened, axial length $24 \mathrm{~mm}$, Impression: Vitreous hemorrhage OS.

Image of OCT Makula OD

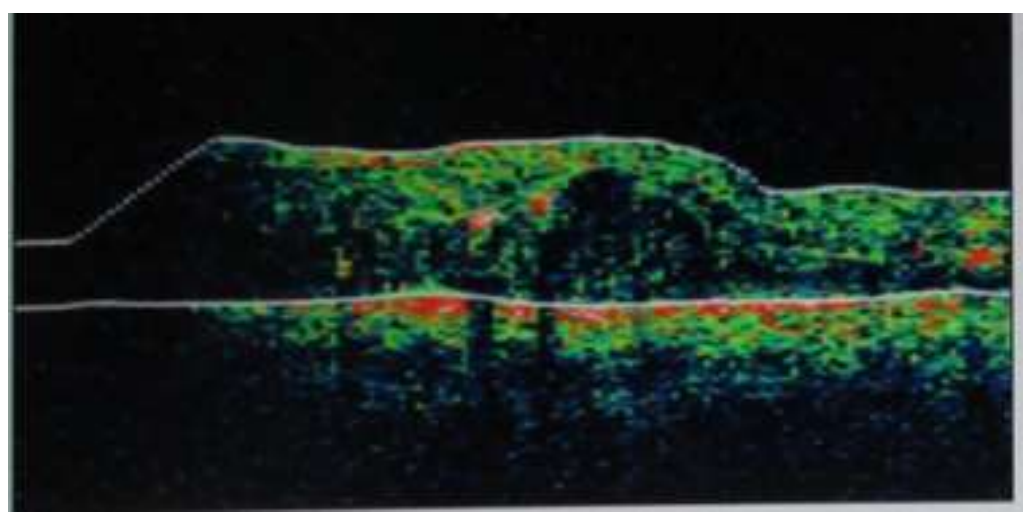

Foveal thickness: $376 \pm 0 \mu \mathrm{m}$ 


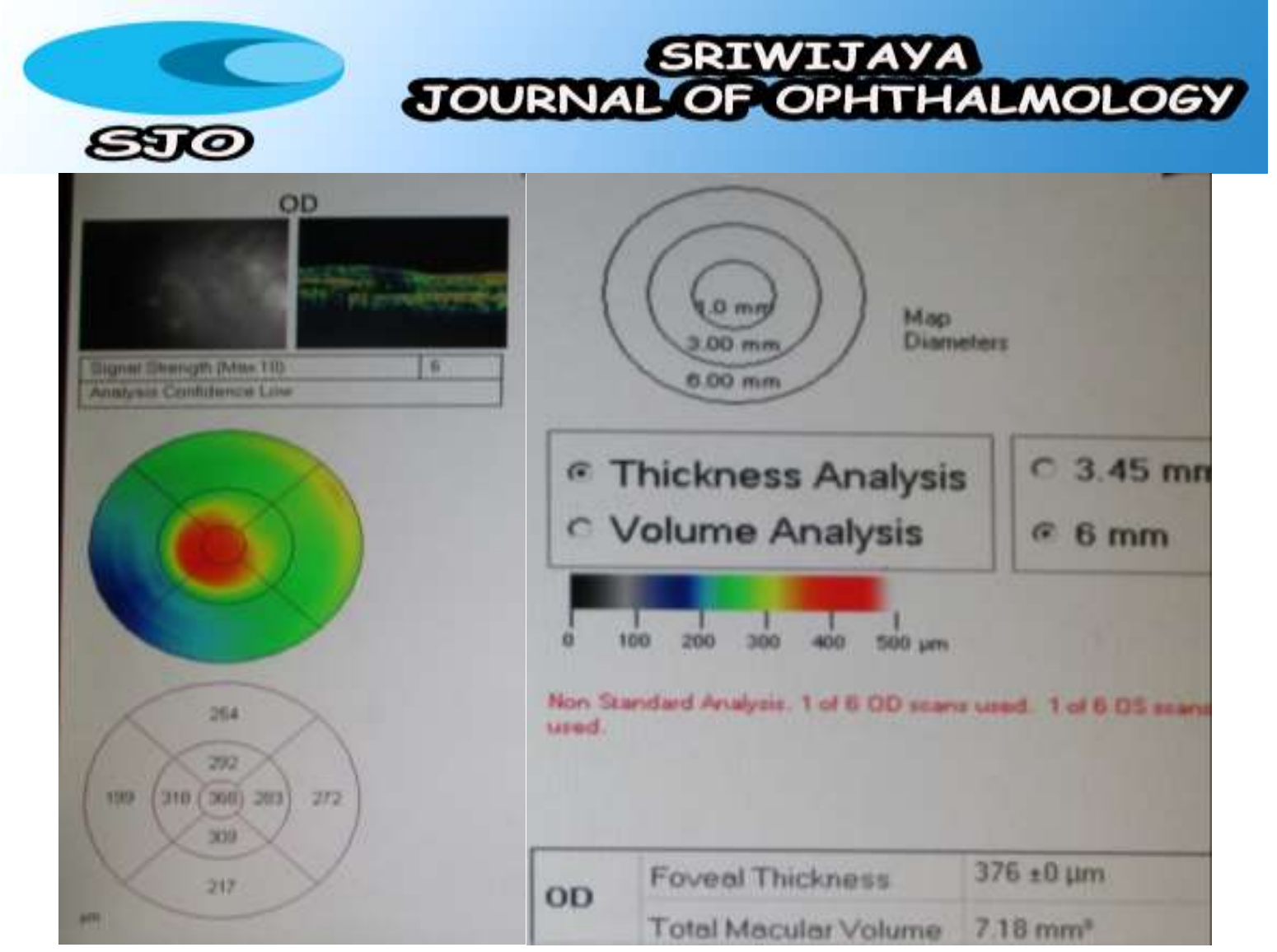

Management is Informed Consent, MRS, Laboratory Examination, X-ray chest X-ray, Pro Internal Medicine consul, Pro Pars Plana Vitrectomy + Endolaser + intravenous injection of antiVEGF (Bevacizumab) OS with general anesthesia, Pro Laser photocoagulation OD. Prognosis of Quo ad vitam: Bonam, Quo ad fungsionam: Dubia ad bonam.

\section{Discussion}

The patient is a 52-year-old man who came with the main complaint that both eyes have blurred slowly since \pm 6 months ago. Blurred vision is not accompanied by red eyes, there is smoke-like vision, views such as seeing in tunnel (-), pain (-), such as seeing things as flying objects (-), complaints of dizziness and headache are absent. The vision feels increasingly blurred in the left eye since the last 1 month. In the past the history of the disease obtained a history of DM 15 years of irregular control and hypertension of 3 years with regular control, a history of spectacles present.

The ophthalmological examination of the right eye revealed a vision of $6 / 30 \mathrm{pH}(-)$, TIOD within normal limits, and a grade II nuclear cataract in the lens. Right eye fundoscopy revealed decreased foveal reflexes and exudates in the macula, dot, blot, flame-shaped bleeding in 4 quadrants of the retina, exudate, venous beading, micro-aneurism. But no NVD, NVE, vitreous haemorrhage, and fibrovascular tissue were found. At the OCT examination of macular OD, 


\section{Serwand JOURNALOFOPHTHALMOLOGY}

\section{हST)}

the thickness of the fovea was $376 \pm 0 \mu \mathrm{m}$. This leads to severe NPDR and DME criteria in the right eye.

Whereas on the ophthalmological examination of the left eye, visual acuity of 1/60 pH () was found, TIOS was within normal limits, and Grade II nuclear cataracts were found on the lens. Left eye fundoscopy revealed vitreous bleeding and details of papules, macules and retina that were difficult to assess. This leads to the advanced PDR criteria. In PDR, fragile neovascularization proliferates to the posterior surface of the vitreous and will arise as the vitreous begins to contract away from the retina. If the blood vessels rupture, massive vitreous bleeding can cause sudden sharp deterioration in vision.

To evaluate the posterior segment, an orbital ultrasound examination is performed. Ultrasound examination of OS showed echogenic with moderate reflectivity and high mobility in vitreous and was interpreted as vitreous bleeding. There were no features of retinal detachment on ultrasound.

From the history, ophthalmological examination, fundoscopy, ultrasound and macular OCT, the patient is diagnosed with Severe NPDR OD + DME OD, Advanced PDR OS, and Grade II ODS nuclear cataracts. Patients aged 52 years and a history of DM for 15 years. This is consistent with the literature which says that the prevalence of RD in people with diabetes mellitus increases with age and duration of diabetes. As many as $50 \%$ of patients with severe NPDR and $75 \%$ of patients with very severe NPDR develop PDR within 1 year.

Management in these patients is pars plana vitrectomy, endolaser, and intravenous OS anti-VEGF injection under general anesthesia. Whereas the right eye was intravitreal photocoagulation laser and anti-VEGF laser (done 2 weeks before). Pars plana vitrectomy is indicated in cases of vitreous bleeding that do not decrease for 1-3 months. This action is intended to completely remove the vitreous cortex and all fibrovascular tissue, then treat retinal tears if found. Vitrectomy in this case also opens the visual axis that is closed by vitreous bleeding. Clear informed consent was carried out regarding the risks and complications of the vitrectomy, one of which was the possibility of the formation of post-rectectomy complicated cataracts.

Laser photocoagulation is recommended for macular edema and PDR conditions. This action aims at increasing oxygenation, overcoming inner retinal hypoxia, resulting in decreased stimulus of proliferation factors in blood vessels, and ultimately reducing or stopping neovascularization. Increased oxygen pressure also causes vasoconstriction thereby increasing 
SSTO

arteriolar resistance, decreasing hydrostatic pressure in capillaries, and reducing edema formation.

Intravitreal anti-VEGF can reduce leakage and cause regression of diabetic neovascularization. Anti-VEGF agents bind and inhibit the biological activity of all VEGF forms and their derivative products, thereby inhibiting the formation of neovascularization. Anti-VEGF drugs in addition to vitrectomy have been shown to help reduce bleeding during surgery and to reduce the incidence of postoperative recurrent retinal bleeding.

The sharp vision of the left eye progressed to 2/60 one day after surgery and the detailed fundus-copy of the left eye was still difficult to assess. Seventeen days postoperatively, the control sufferer with complaints of left eye sight again felt blurred. Examination obtained VOS 1/300 and complicated cataracts with a shadow test (-) on the left eye lens. The formation of post-vitrectomy cataracts is thought to be related to structural disruption of the vitreous body which causes increased oxygen exposure to the lens and thus results in the formation of nuclear cataracts. In addition, maneuvers performed intraoperatively can affect the lens and capsule, resulting in humorous humor or the body of the corpus vitreus can enter the lens structure so that the lens quickly becomes cloudy. In patients with cataract extraction using Small Incision Cataract Surgery (SICS) and IOL implants in the left eye. Sharp vision of the left eye becomes $6 / 12 \mathrm{pH}(-)$ on the 7th day postoperatively. In left eye fundoscopy there is an advanced NPDR with clinical improvement. This shows the progress of the therapeutic results.

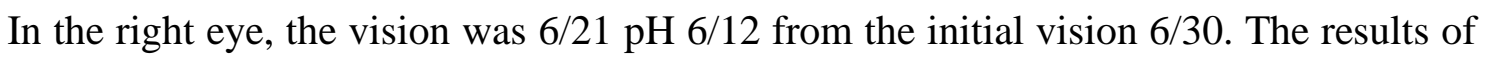
macular OD OCT showed a reduction in fovea edema from $376 \pm 0 \mu \mathrm{m}$ to $290 \pm 14 \mu \mathrm{m}$ resulting in a sharp improvement in vision.

\section{Conclusion}

A case of advanced left eye PDR with severe NPDR and right eye DME and grade II nuclear cataracts has been described in both eyes. Patients treated with laser photocoagulation in the right eye. In the left eye pars plana vitrectomy, endolaser, and intravitreal bevacizumab injection. Sharp vision of the left eye progressed postoperatively.

Cataracts formed after vitrectomy are thought to be related to disruption of the vitreous body structure which causes increased oxygen exposure to the lens, resulting in the formation of nuclear cataracts. In addition, intraoperative maneuvers can affect the lens and capsule, resulting in humorous humor or the body of the vitreous corpus can enter the lens structure so 
that the lens quickly becomes cloudy. Cataract extraction is carried out with SICS and IOL implant techniques on the left eye. Sharp final vision is obtained 6/12 compared to $1 / 300$ at the beginning.

\section{References}

1. Boyd S, Girach A, Pelayes DE. Diagnosis and Treatment of Diabetic Retinopathy. Jaypee-Highlights Medical Publishers. 2010.

2. Skuta GL, Cantor LB, Weiss JS, et al. Retina and Vitreous. American Academy of Ophthalmology Chapter 5 \& 15. 2011-2012; 109-132, 363.

3. Skuta GL, Cantor LB, Weiss JS, et al. Retina and Vitreous. American Academy of Ophthalmology Chapter 5,16,17. 2011-2012; 89-112, 337-354.

4. Pedoman Penanganan Retinopati Diabetika. Persatuan Dokter Spesialis Mata Indonesia Seminat Vitreoretina. 2013.

5. International Council of Ophthalmology. ICO Guidlines for Diabetic Eye Care. ICO, January 2014;1-32.

6. Kansky JJ, Bowling B. Clinical Ophthalmology: Seventh edition. Elsevier. 2011; p534-550.

7. Brinton DA, Wilkinson CP. Retinal Detachment : Principles and Practice. 3rd Edition. Oxford. 2009; 212-217.

8. Duker CS, Macsai MS. Rapid Diagnoses in Ophthalmology : Retina. Mosby Elsevier. 2008;1-13.

9. Ryan SJ. Retina. Fourth Edition. Volume I. Mosby Elsevier. 2006.

10. Yannuzi LA. The Retinal Atlas. Saunders Elsevier. 2010;441-466.

11. Fletcher EC, Chong NHV, Shetlar DJ. Retinopati Diabetik. Vaughan \& Asbury Oftalmologi Umum. Jakarta: EGC; 2012:p190-193.

12. Bloom, Steven, Brucker. Laser Surgery of the Posterior Segment. Second Edition. Lippincott-Raven.

13. Joussen, et al. Retinal Vascular Disease. Springer. 2007; p260-267.

14. Peyman GA, Meffert SA, Conway MD. Vitreoretinal Surgical Techniques, second edition. Informa. 2007; 256-257. 
15. Arevalo JF, Shancez CG, et al. Intravitreal Bevacizumab (Avastin) for Diabetic Retinopathy : The GLADAOF 2010 Lecture. Journal of Ophthalmology, Hindawi Publishing. Vol 2011; p1-13.

16. Do DV, Gichuhi S, et al. Surgery for post-vitrectomy cataract (Review). The Cochrane Collaboration. 2013. Issue 12.

17. Jim Dryden. Oxygen near lens linked to cataracts in eye surgery patients. 2005. Available at : http://news.wustl.edu/news/Pages/4986.aspx dy Removal. Tech Ophthalmology. 2009. 